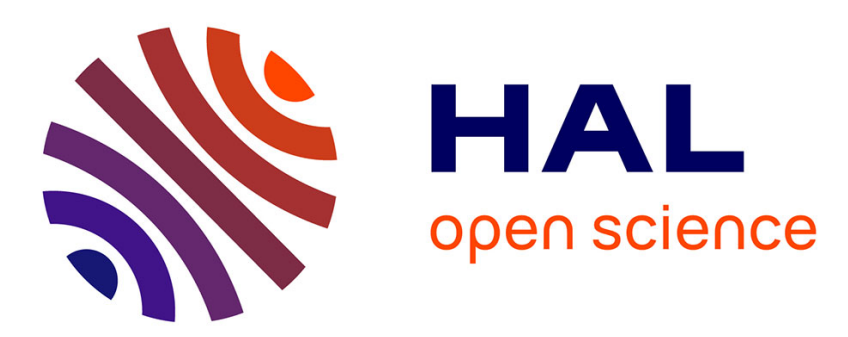

\title{
Long-term functional results and quality of life after redo rectal surgery: delayed versus immediate colo-anal anastomosis
}

H. Boullenois, J. H. Lefevre, B. Creavin, T. Voron, C. Debove, N. Chafai, Y. Parc

\section{To cite this version:}

H. Boullenois, J. H. Lefevre, B. Creavin, T. Voron, C. Debove, et al.. Long-term functional results and quality of life after redo rectal surgery: delayed versus immediate colo-anal anastomosis. Colorectal Disease, In press, 10.1111/codi.14983 . hal-02530679

\section{HAL Id: hal-02530679 \\ https://hal.sorbonne-universite.fr/hal-02530679}

Submitted on 3 Apr 2020

HAL is a multi-disciplinary open access archive for the deposit and dissemination of scientific research documents, whether they are published or not. The documents may come from teaching and research institutions in France or abroad, or from public or private research centers.
L'archive ouverte pluridisciplinaire HAL, est destinée au dépôt et à la diffusion de documents scientifiques de niveau recherche, publiés ou non, émanant des établissements d'enseignement et de recherche français ou étrangers, des laboratoires publics ou privés. 


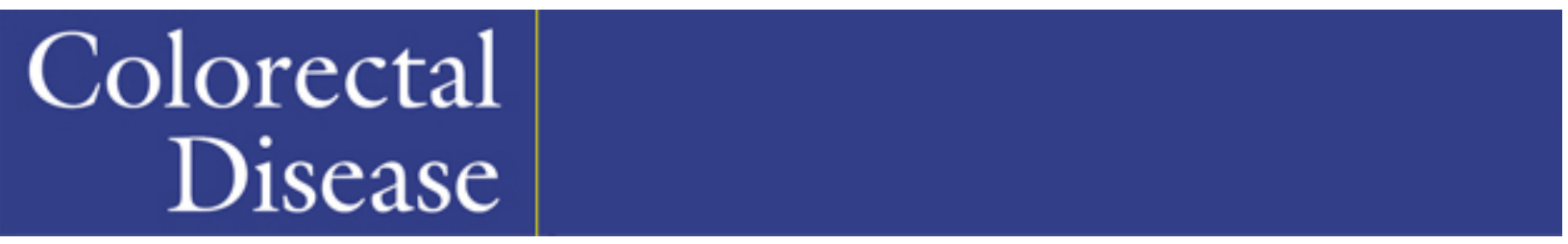

\section{Long term functional results and quality of life in rectal redo surgery: delayed vs. immediate colo-anal anastomosis, a case-matched study of 52 patients.}

\begin{tabular}{|c|c|}
\hline Journal: & Colorectal Disease \\
\hline Manuscript ID & CDI-00732-2019.R2 \\
\hline Wiley - Manuscript type: & Original Article \\
\hline $\begin{array}{r}\text { Date Submitted by the } \\
\text { Author: }\end{array}$ & $n / a$ \\
\hline Complete List of Authors: & $\begin{array}{l}\text { Boullenois, Hortense; Hopital Saint-Antoine, General Surgery } \\
\text { Lefevre, Jeremie; Hopital Saint-Antoine, General Surgery } \\
\text { Creavin, Ben; St Vincent's Hospital, department of surgery } \\
\text { voron, thibault; Hopital Saint-Antoine, General Surgery } \\
\text { debove, clotilde; Hopital Saint-Antoine, General Surgery } \\
\text { Chafai, Najim; Hopital Saint-Antoine, General Surgery } \\
\text { Parc, Yann; Assistance Publique - Hopitaux de Paris, Paris }\end{array}$ \\
\hline Specialty area: & cancer \\
\hline Abstract: & 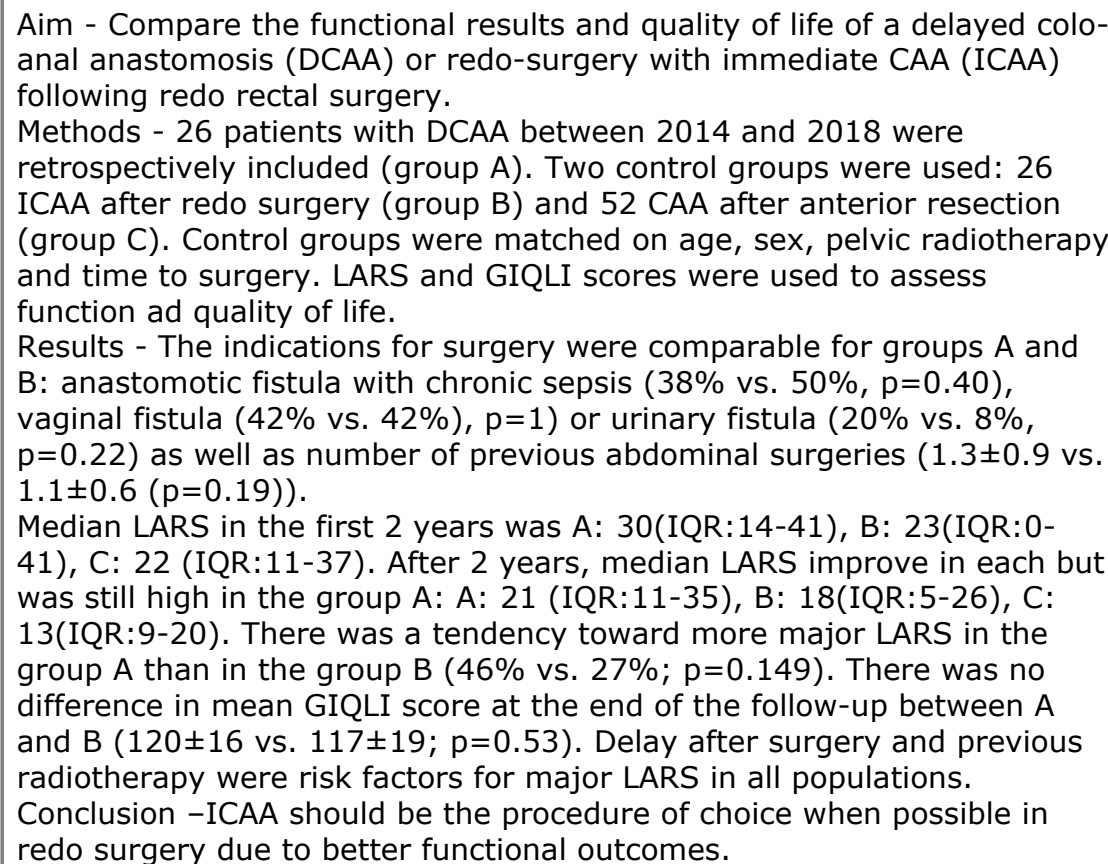 \\
\hline
\end{tabular}




\section{SCHOLARONE" Manuscripts}


Long term functional results and quality of life in rectal redo surgery: delayed vs. immediate colo-anal anastomosis, a case-matched study of 52 patients.

Hortense Boullenois ${ }^{1}$ (MD), Jérémie H. Lefevre ${ }^{1}(\mathrm{MD}, \mathrm{PhD})$, Ben Creavin ${ }^{2}$ (MD), Thibaut Voron ${ }^{1}(\mathrm{MD})$, Clotilde Debove ${ }^{1}(\mathrm{MD})$, Najim Chafai ${ }^{1}(\mathrm{MD})$, Yann Parc ${ }^{1}(\mathrm{MD}, \mathrm{PhD}){ }^{1}$

1. Sorbonne Université, Department of Digestive Surgery, AP-HP, Hôpital Saint Antoine, F-75012, Paris, France.

2. Department of Surgery, St Vincent's University Hospital, Elm Park, Dublin 4, Ireland

\section{Correspondence:}

Professor Jérémie LEFEVRE (MD, PhD)

Department of Digestive Surgery, Saint Antoine Hospital, 184 rue du Faubourg Saint Antoine, 75012 Paris, France.

Tel.: +331492826 87; fax: +33149282548

E-mail: jeremie.lefevre@aphp.fr

Keywords: Delayed colo-anal anastomosis; redo rectal surgery; colo-anal anastomosis; LARS score; GIQLI score.

Funding: None

Word count: 2915

Disclosure to report: no disclosure to report. 


\section{ABSTRACT}

Aim - Compare the functional results and quality of life of a delayed colo-anal anastomosis (DCAA) or redo-surgery with immediate CAA (ICAA) following redo rectal surgery.

Methods - 26 patients with DCAA between 2014 and 2018 were retrospectively included (group A). Two control groups were used: 26 ICAA after redo surgery (group B) and 52 CAA after anterior resection (group C). Control groups were matched on age, sex, pelvic radiotherapy and time to surgery. LARS and GIQLI scores were used to assess function ad quality of life.

Results - The indications for surgery were comparable for groups A and B: anastomotic fistula with chronic sepsis ( $38 \%$ vs. $50 \%, \mathrm{p}=0.40)$, vaginal fistula $(42 \%$ vs. $42 \%), \mathrm{p}=1)$ or urinary fistula $(20 \%$ vs. $8 \%, \mathrm{p}=0.22)$ as well as number of previous abdominal surgeries $(1.3 \pm 0.9$ vs. $1.1 \pm 0.6(\mathrm{p}=0.19))$.

Median LARS in the first 2 years was A: 30(IQR:14-41), B: 23(IQR:0-41), C: 22 (IQR:1137). After 2 years, median LARS improve in each but was still high in the group A: A: 21 (IQR:11-35), B: 18(IQR:5-26), C: 13(IQR:9-20). There was a tendency toward more major LARS in the group A than in the group B (46\% vs. $27 \% ; p=0.149)$. There was no difference in mean GIQLI score at the end of the follow-up between A and B (120 \pm 16 vs. $117 \pm 19$; $\mathrm{p}=0.53$ ). Delay after surgery and previous radiotherapy were risk factors for major LARS in all populations.

Conclusion -ICAA should be the procedure of choice when possible in redo surgery due to better functional outcomes. 
What does this paper add to the literature?

In redo rectal surgery, delayed colo-anal anastomosis can be an alternative to immediate anastomosis, but functional results are not well known. This study brings new data in rectal redo-surgery finding that immediate anastomosis allows better functional results than a delayed one and should be the procedure of choice. 


\section{INTRODUCTION}

Oncologic rectal resection is associated with significant morbidity and mortality independent of oncological outcomes. While a Total Mesorectal Excision (TME) remains the gold standard treatment for rectal cancer, organ preservation strategies have been developed to avoid a TME and anastomosis formation, however, this is not feasible in all cases. A diverting stoma has been shown to protect against overwhelming sepsis from leaks when anastomotic fistula (AF) happens, which rates around 20\%. [1] Acute management of AF includes drainage or reoperation. [2-5] If stoma closure is desired, redo surgery with the formation of a new anastomosis is sometimes required. This surgery is complex, with several techniques reported. Redo surgery with the creation of a redo-surgery with immediate handsewn coloanal anastomosis (ICAA) has good success rates. [6, 7] When local factors increase the risk of failure, including chronic pelvic sepsis and very low AF urinary (UF) or vaginal fistula (VF), redo surgery with delayed anastomosis (DCAA) can be utilised. [8] Some authors advocate this anastomosis for almost all redo surgeries. Success of this two-step anastomosis has been recently published but functional results and quality of life of this very low anastomosis, almost a colo-cutaneous anastomosis, are lacking. [8] Published studies include very small sample sizes and mainly consider feasibility and success of this technique.

Delayed colo-anal anastomosis was initially described by Cutait and Turnbull in rectal surgery for Hirschrpung's disease. [9, 10] Later, this two-stage anastomosis technique was performed for rectal cancer surgery to reduce the risk of AF and avoid a diverting stoma. [11] It was finally abandoned due to unconvincing results. Currently, this technique is rarely used as the primary surgical intervention for cancer due to persistant $\mathrm{AF}$ and poor functional outcomes and is mainly reserved for redo surgeries. 
The aim of this study was to evaluate long-term functional outcomes and quality of life after redo-surgery with DCAA and compare it to ICAA and primary colo-anal anastomosis for cancer (CAA).

\section{METHODS}

\section{Study populations}

All patients who had a DCAA for redo-surgery with stoma closure (named group A) between January 2014 and June 2018 were included. Two control groups were created with patients randomly selected from cohorts during the same period. The ICAA control group (named group B) was composed of patients who underwent redo-surgery with immediate colo-anal anastomosis and stoma closure (1 for 1), while the CAA control group (named group C) composed of patients who underwent primary anterior resection with colo-anal anastomosis for low rectal adenocarcinoma (2 for 1$)$ and stoma closure. Control groups were matched to the group A for age, gender, history of pelvic radiotherapy and interval to stoma closure. Patients were excluded if a secondary stoma formation was required for oncological, septic or functional reasons.

Data was collected retrospectively in an anonymous database. Patient specific factors including, age, gender, previous pelvic surgery, previous anastomosis and history of pelvic radiotherapy were collected. Surgical data included stoma formation, type of stoma (colostomy or ileostomy), associated colonic lengthening technique (Toupet or Deloyer procedure) and interval to stoma closure.

\section{Surgical technique}

In group A, patients underwent the first stage of the redo-surgery through a midline laparotomy approach. This technique has been described previously. [8] The second operative 
procedure (colonic stump resection and handsewn redo-surgery with colo-anal anastomosis) was performed by perineal approach approximately 14 days later.

In group $\mathrm{B}$, the redo-surgery was also performed through a midline laparotomy, with a handsewn end to end colo-anal anastomosis formed at the time of surgery. All patients had temporary diverting ileostomy. [7]

In group $\mathrm{C}$, a TME approach with anterior resection was performed. [12] Patient specific factors and surgeon preference determined the approach (laparoscopic vs laparotomy). The anastomosis was either handsewn or stapled, with a redo-surgery with straight, side-to-end or a J-pouch formed. All patients had a temporary diverting ileostomy.

Stoma closure was performed following physical exam and an opacified CT scan to rule out asymptomatic anastomotic leak.

The choice of the surgical technique was based on the clinical evaluation and surgical history of the patient. A DCAA was preferred when the pelvic sepsis was major, the fistula was very low or after several failures of ICAA which lead to fear the failure of a new ICAA.

\section{Functional results}

Functional results were evaluated with two scores collected by phone call for all patients at the end of the follow-up.

LARS score (Low Anterior Resection Syndrome score) is a validated functional score for evaluation of functional outcomes after rectal surgery. [13] It consists of 5 questions, each with 3 to 4 possible answers. For each answer, proposition values are associated with a number of points from 0 to 16 . The sum of the scores determines the value of the LARS score, from 0 to 42 . There are three scoring levels: no LARS (score between 0 and 20), minor LARS (score between 21 and 30) and major LARS (score between 31 and 42). The higher the score, the higher the post-operative functional symptoms: stool or gas leakage, number of 
stools, urge symptoms, fragmentation which corresponds to the incomplete evacuation of the stool leading to several close evacuations in one hour, consequence of defect of the defecation function after anterior rectal resection.

The GIQLI (GastroIntestinal Quality of Life Index) is a quality of life score validated for digestive pathologies. [14] It is composed of 36 items with scores ranging from 0 to 4 depending on the frequency or severity of the symptoms ( 0 being the worst and 4 being the best). This score is evaluated on the symptoms present for the two-week period prior to the assessment. The questionnaire explores 4 domains: symptoms (19 items), physical conditions (7 items), emotions (5 items) and social integration (5 items).

\section{Endpoints:}

The primary endpoint was the comparison of functional results evaluated with LARS score and GIQLI at the end of the follow-up in the three groups.

Secondary endpoints included the evolution of functional scores over time following stoma closure and the evaluation of predictive factors of major LARS.

\section{Statistical analysis:}

Quantitative variables were expressed as means ( \pm standard deviation, SD) /median and range, with qualitative variables as frequencies (percentages). A Mann-Whitney U test was used for intergroup comparisons of quantitative variables, whereas a chi-square test was used to compare categorical data. A value of $\mathrm{p}<0.05$ was considered significant. Statistical analyses were performed using the R software.

\section{RESULTS}

Clinical and surgical characteristics 
A total of 39 consecutive DCAA were performed between January 2014 and June 2018, of which 26 patients were included in the present study. 13 patients were excluded due to loss to follow-up ( $n=6)$, presence of a stoma $(n=6)$, or death $(n=1)$. Control groups were composed of 26 ICAA and 52 CAA. Patients were well matched on age, gender, previous pelvic radiotherapy and interval between stoma closure and evaluation of functional results (global delay, delay $<1$ year and delay $<2$ years). (Table 1)

Primary diagnosis was mostly rectal cancer in the redo surgery groups (A: $n=20$ (77\%), B: $\mathrm{n}=18(70 \%) ; \mathrm{p}=0.53)$. Indications of redo-surgery did not differ between $\mathrm{A}$ and $\mathrm{B}(\mathrm{p}=0.432)$. Associated colonic lengthening technique (Toupet or Deloyer procedure) was performed for 8 (31\%) patients in group A, and $12(46 \%)$ patients in group $B(p=0.25)$. All redo-surgery and $71 \%$ of CAA were handsewn anastomoses. After DCAA, 6 patients $(23 \%)$ had no diverting stoma. Median interval to stoma closure was 2.4 (IQR 2.0-3.1) months in group A, 2.6 (IQR 2.1-3.6) in group B, and 3.1 (IQR 2.2-4.4) months in group C.

\section{Primary endpoint.}

At the end of the follow-up, group C was associated with better LARS \& GIQLI scores (19 $(\mathrm{IQR}=15-32)$ and $12(\mathrm{IQR}=108-144)$. Tendency of worse outcomes were noted in the group A compared to the group C (LARS: $p=0.057$; GIQLI: $p=0.066$ ). In the redo surgery groups (A vs. B), LARS and GIQLI scores did not differ significantly ( $\mathrm{p}=0.292$ and $\mathrm{p}=0.728$, respectively). (Figures 1a \& 1b). However, there was a tendency toward more major LARS in the group A than in the group B (46\% vs. $27 \%$; $=0.149)$. The rates of major LARS were similar between groups B and C (27\%). (Table 2)

The five LARS score criteria were evaluated in each group. Apart from fragmentation, functional results were better in group $\mathrm{C}$ than after redo surgery and in group B compared to group A. (Table 3) 
Outcomes at the end of follow up are presented in table 3. Median scores were higher for "emotion" ( $p=0.028)$ and lower for "social integration" ( $p=0.047)$ in group A compared to group B. After redo surgery, there was a major modification in eating habits and sexual activity.

\section{Secondary endpoints}

Subgroup analysis was performed in each group $(<2$ years post stoma closure vs $>2$ years post stoma closure). Both LARS and GIQLI scores improved in each group over time although this was not statistically significant. (Figures 2a \& b). A significant improvement in major LARS was observed in the group C over time ( $41 \%$ vs. $12 \%, p=0.04)$. (Table 2$)$

In group A, a reduction in the number of stools per day, fragmentation and urges was observed over time, although there was minimal improvement in stool and gas incontinence.

\section{Predictive factors of major LARS score}

In univariate analysis, previous radiotherapy and interval since stoma closure were predictive factors of a major LARS score. Gender, age, number of anterior anastomoses and associated colonic lengthening procedures did not appear to be predictive factors for major LARS after redo surgery. In group C, male gender also appeared as a predictive factor of major LARS score. (Table 4)

\section{DISCUSSION}

The present study reports on a series of 26 DCAA for redo rectal surgery between January 2014 and August 2018. The authors previously reported a high success rate of DCAA with a low morbidity [8], however, this series showed that functional results evaluated with LARS score seem to be better after ICAA than after DCAA, with no difference in quality of life. All 
symptoms of LARS score were more intense in group A. Both functional results and quality of life improved with time after redo surgery. This too is true in group C. However, a major reduction in fragmentation, number of stools per day and urgency was observed compared with incontinence of gas and stools.

To our knowledge, this series presents one of the first cohorts of patients with functional outcomes and long-term quality of life after redo-surgery. Moreover, it is the only one that compares DCAA to ICAA in redo-surgery. Management of chronic AF, VF and UF after pelvic surgery is complex. After failure of conservative treatments (local repairs, advancement flaps, epiploplasty), invasive surgery should be considered. In redo-surgery, ICAA is usually preferred to DCAA principally due to the lack of data concerning functional results after DCAA. Few studies with small numbers report success, functional results and quality of life after DCAA. [6, 7, 15] Only Maggiori et al. reported a series of 24 DCAA for redo-surgery. [16]

Rectal resection leads to functional disorders whose physiopathology is complex. This can be explained by sphincter dysfunction (inter-sphincteric resection, use of staplers, extensive mucosectomy, nerve lesions and radiotherapy) and absence of rectal function (compliance and reservoir). [17] In 2012, Bryant explained the concept of low anterior rectal resection syndrome, describing its negative impact on quality of life. [18] Symptoms were then evaluated with LARS score created by Bregendahl. [19] Several risk factors are associated with poor function following rectal resection: age, radiotherapy, extent of rectal resection and mucosectomy, anastomotic leakage, creation of a J-pouch and interval after surgery. $[3,20$, 21] Therefore, impaired function after redo rectal surgery is easily understood, especially in DCAA with a very low anastomosis. The present study choose to match groups with age, gender, history of radiotherapy and interval between surgery and evaluation of functional scores in order to give a homogenous group to analyse. 
Moreover, evolution of functional disorders after rectal resection is poorly described in the literature, although it seems that function improves with time, even up to two years post-operatively. Thus, we analysed the effect of post-operative delay on functional disorders and quality of life, selecting 2 groups based on time interval $(>$ or $<2$ years post stoma closure). As expected, the results confirmed an improvement in LARS score with a longer interval from stoma closure in group $\mathrm{A}$ as in the control groups. This was not significant $(\mathrm{p}=0.12)$, however, median LARS scores reduced from major to minor in the group A. Similarly, no significant difference was seen in the control group, however, a trend towards no LARS after 2 years was seen in groups B and C.

Several scoring tools are used to evaluate functional results after rectal surgery. The present study used the LARS score as it is the most commonly used tool and allowed comparison with other publications. Moreover, it is easier to use than MSKCC-BFI score and preferred to the Wexner score which evaluates incontinence more specifically. LARS score was specifically created to evaluate anterior resection syndrome. [13] Concerning the quality of life score, as the EORTC-QLQ has been proven to be correlated to the LARS score, we choose to use another score the GIQoL. [22]

Although LARS is altered after surgery and seemed to be worse in group A compared to group B, it was interesting to see no difference in quality of life between these groups. The GIQLI score was used in the present study as it is a validated score to evaluate the quality of life after surgery for digestive disorders and gathers a large evaluation of symptoms, emotions, social integrations and activities. Our results showed that there was no difference in quality of life between group A and B, with an improvement in quality of life over time (Figure 1 and 2). Absence of statistical difference could be explained by the small number of patients in each sub-group and the choice of the 2 years cut off. 
There were several limitations in the present study. Firstly, this is a retrospective study with a small number of patients, thus impacting on the statistical power of the study. Indeed, even in specialized tertiary centres, this technique is rare. It is however the largest series of DCCA in redo-surgery which analysed functional results and quality of life, comparing it to ICAA. Matching criteria for the study was based on the most influential factors of dysfunction after rectal surgery. Post-operative cares as biofeedback didn't appeared as bias in evaluation of functional long-term results since none of our patients practiced pelvic biofeedback and pelvic physiotherapy. Actually, these practices are not developed in our center as in most tertiary rectal surgery centers in our region. Comparison with a control group of patients with definitive stoma after pelvic surgery didn't seem justified, since all patients are referred to our centre in order to reverse their stoma. Moreover, it has been established that the quality of life of these patients, whose mean age is 60 , is significantly altered, with no patient wishing to have a stomal reversal due to poor quality of life even with a low GIQLI score. We choose to create a control group with several types of CAA (handsewn, stapled, redo-surgery with immediate, side-to-end or with a J-pouch) in order to have a group that represents the global population. As previously mentioned, there are a number scoring tools to assess both functionality and quality of life. While the LARS scoring tool has been created specifically to evaluate low anterior resection syndrome and has been validated in large series, its interpretation is not necessarily correlated with importance of symptoms. [23, 24] Inclusion of quality of life evaluation in the present study further added to the strength of this study.

The results in the present study are new and force us to reconsider the choice of DCAA in redo-surgery. It is now known that this is a safe technique, with a high success rate especially in cases where the formation of the initial anastomosis is risky. However, LARS score seemed to be better following ICAA which would make us concluded that proceeding to 
a ICAA when possible is the best option. Further studies are required to validate this statement and determine major risk factors for failure of DCAA, poor functional results and the appropriateness of a DCAA procedure over an ICAA. In the present series, indications for redo-surgery were not different in the two groups, highlighting the possibility of an ICAA approach for the majority of patients.

Even if the functional results are undeniably altered, there are a number of options available to patients with major LARS. Biofeedback has been successful in a series of 22 patients after rectal resection for cancer, improving stool incontinence, number of stools, dyschesia and quality of life.[25] Retrograde irrigation was evaluated in 26 patients after anterior resection and found to completely or partially improve symptoms for some patients. [26] Sacral neuromodulation, used more often in vesical dysfunction, has shown interesting preliminary results. $[27,28]$

In redo surgery, delayed colo-anal anastomosis is an alternative to redo-surgery with immediate anastomosis in complex pelvic situations. Although success rates are high, functional results and quality of life were not known. This retrospective comparative study showed that there was no statistical difference in LARS or quality after redo-surgery between immediate or delayed anastomosis, even if a tendency in favour of an immediate anastomosis was observed. Both functional results and quality of life improved with time. An interval of less than 2 years since stoma closure and previous pelvic radiotherapy appeared to be predictive factors of major LARS after redo surgery. An immediate anastomosis should be the preferred anastomotic technique for redo-surgery. The delayed anastomosis should be reserved for complex cases and patient should be warned of the poor functional results in the first 2 years. Alternative medical therapies must be developed and proposed for patients who have major LARS after two years. 


\section{REFERENCES}

1. Matthiessen P, Hallbook O, Rutegard J, Simert G, Sjodahl R. Defunctioning stoma reduces symptomatic anastomotic leakage after low anterior resection of the rectum for cancer: a randomized multicenter trial. Ann Surg 2007; 246: 207-14.

2. Challine A, Lefevre JH, Creavin B, Benoit O, Chafai N, Debove C, et al. Can a local drainage salvage a failed colo-rectal or colo-anal anastomosis? A prospective cohort of 54 patients. Dis Colon Rectum 2019

3. Lakkis Z, Manceau G, Bridoux V, Brouquet A, Kirzin S, Maggiori L, et al. Management of rectal cancer: the 2016 French guidelines. Colorectal Dis 2017; 19: 115-22.

4. Lefevre JH, Mineur L, Kotti S, Rullier E, Rouanet P, de Chaisemartin C, et al. Effect of Interval (7 or 11 weeks) Between Neoadjuvant Radiochemotherapy and Surgery on Complete Pathologic Response in Rectal Cancer: A Multicenter, Randomized, Controlled Trial (GRECCAR-6). J Clin Oncol 2016; 34: 3773-80.

5. den Dulk M, Smit M, Peeters KC, Kranenbarg EM, Rutten HJ, Wiggers T, et al. A multivariate analysis of limiting factors for stoma reversal in patients with rectal cancer entered into the total mesorectal excision (TME) trial: a retrospective study. Lancet Oncol 2007; 8: 297-303.

6. Lefevre JH, Bretagnol F, Maggiori L, Ferron M, Alves A, Panis Y. Redo surgery for failed colorectal or coloanal anastomosis: a valuable surgical challenge. Surgery 2011; 149: $65-71$.

7. Pitel S, Lefevre JH, Tiret E, Chafai N, Parc Y. Redo coloanal anastomosis: a retrospective study of 66 patients. Ann Surg 2012; 256: 806-10; discussion 10-1.

8. Boullenois H, Lefevre JH, Creavin B, Calmels M, Voron T, Debove C, et al. What is the functional result of a delayed coloanal anastomosis in redo rectal surgery? ANZ J Surg 2019; 89: E179-E83.

9. Cutait DE, Figliolini FJ. A new method of colorectal anastomosis in abdominoperineal resection. Dis Colon Rectum 1961; 4: 335-42.

10. Turnbull RB, Jr., Cuthbertson A. Abdominorectal pull-through resection for cancer and for Hirschsprung's disease. Delayed posterior colorectal anastomosis. Cleve Clin $Q$ 1961; 28: 109-15. 
11. Cutait DE, Cutait R, Ioshimoto M, Hyppolito da Silva J, Manzione A. Abdominoperineal endoanal pull-through resection. A comparative study between immediate and delayed colorectal anastomosis. Dis Colon Rectum 1985; 28: 294-9.

12. Bennis M, Parc Y, Lefevre JH, Chafai N, Attal E, Tiret E. Morbidity risk factors after low anterior resection with total mesorectal excision and coloanal anastomosis: a retrospective series of 483 patients. Ann Surg 2012; 255: 504-10.

13. Emmertsen KJ, Laurberg S. Low anterior resection syndrome score: development and validation of a symptom-based scoring system for bowel dysfunction after low anterior resection for rectal cancer. Ann Surg 2012; 255: 922-8.

14. Eypasch E, Williams JI, Wood-Dauphinee S, Ure BM, Schmulling C, Neugebauer E, et al. Gastrointestinal Quality of Life Index: development, validation and application of a new instrument. Br J Surg 1995; 82: 216-22.

15. Genser L, Manceau G, Karoui M, Breton S, Brevart C, Rousseau G, et al. Postoperative and long-term outcomes after redo surgery for failed colorectal or coloanal anastomosis: retrospective analysis of 50 patients and review of the literature. Dis Colon Rectum 2013; 56: 747-55.

16. Maggiori L, Blanche J, Harnoy Y, Ferron M, Panis Y. Redo-surgery by transanal colonic pull-through for failed anastomosis associated with chronic pelvic sepsis or rectovaginal fistula. Int J Colorectal Dis 2015; 30: 543-8.

17. Sarcher T, Dupont B, Alves A, Menahem B. Anterior resection syndrome: What should we tell practitioners and patients in 2018? J Visc Surg 2018; 155: 383-91.

18. Bryant CL, Lunniss PJ, Knowles CH, Thaha MA, Chan CL. Anterior resection syndrome. Lancet Oncol 2012; 13: e403-8.

19. Bregendahl S, Emmertsen KJ, Lous J, Laurberg S. Bowel dysfunction after low anterior resection with and without neoadjuvant therapy for rectal cancer: a population-based cross-sectional study. Colorectal Dis 2013; 15: 1130-9.

20. Denost Q, Laurent C, Capdepont M, Zerbib F, Rullier E. Risk factors for fecal incontinence after intersphincteric resection for rectal cancer. Dis Colon Rectum 2011; 54: 963-8.

21. Ashburn JH, Stocchi L, Kiran RP, Dietz DW, Remzi FH. Consequences of anastomotic leak after restorative proctectomy for cancer: effect on long-term function and quality of life. Dis Colon Rectum 2013; 56: 275-80. 
22. Emmertsen KJ, Laurberg S, Rectal Cancer Function Study G. Impact of bowel dysfunction on quality of life after sphincter-preserving resection for rectal cancer. $\mathrm{Br}$ J Surg 2013; 100: 1377-87.

23. Juul T, Elfeki H, Christensen P, Laurberg S, Emmertsen KJ, Bager P. Normative Data for the Low Anterior Resection Syndrome Score (LARS Score). Ann Surg 2018

24. Ribas Y, Aguilar F, Jovell-Fernandez E, Cayetano L, Navarro-Luna A, Munoz-Duyos A. Clinical application of the LARS score: results from a pilot study. Int J Colorectal Dis 2017; 32: 409-18.

25. Laforest A, Bretagnol F, Mouazan AS, Maggiori L, Ferron M, Panis Y. Functional disorders after rectal cancer resection: does a rehabilitation programme improve anal continence and quality of life? Colorectal Dis 2012; 14: 1231-7.

26. Koch SM, Rietveld MP, Govaert B, van Gemert WG, Baeten CG. Retrograde colonic irrigation for faecal incontinence after low anterior resection. Int J Colorectal Dis 2009; 24: 1019-22.

27. Ratto C, Grillo E, Parello A, Petrolino M, Costamagna G, Doglietto GB. Sacral neuromodulation in treatment of fecal incontinence following anterior resection and chemoradiation for rectal cancer. Dis Colon Rectum 2005; 48: 1027-36.

28. Schwandner O. Sacral neuromodulation for fecal incontinence and "low anterior resection syndrome" following neoadjuvant therapy for rectal cancer. Int J Colorectal Dis 2013; 28: 665-9. 
Table 1. Clinical and surgical characteristics of patients after delayed colo-anal anastomosis for redo-surgery, immediate colo-anal anastomosis for redo-surgery and first colo-anal anastomosis for cancer.

\begin{tabular}{|c|c|c|c|c|}
\hline & Group A $(n=26)$ & Group B $(n=26)$ & Group C $(n=52)$ & p value \\
\hline $\begin{array}{l}\text { Clinical characteristics } \\
\text { Mean age at surgery } \\
\text { Gender male } \\
\text { Previous radiotherapy } \\
\text { Median follow-up (in months) }\end{array}$ & $\begin{array}{c}59 \pm 13(27-76) \\
14(56 \%) \\
11(42 \%) \\
30(\text { IQR } 24-40)\end{array}$ & $\begin{array}{c}61 \pm 15(28-81) \\
12(46 \%) \\
14(54 \%) \\
33(\text { IQR } 25-49)\end{array}$ & $\begin{array}{c}63 \pm 12(34-90) \\
28(54 \%) \\
30(58 \%) \\
28(\text { IQR } 22-49)\end{array}$ & $\begin{array}{l}0.79 \\
0.44\end{array}$ \\
\hline $\begin{array}{l}\text { Main diagnosis } \\
\text { Rectal adenocarcinoma } \\
\text { Others } \\
\text { Prostate adenocarcinoma } \\
\text { Endometriosis } \\
\text { Rectal ischemic stenosis } \\
\text { Hirschsprung disease } \\
\text { Ovarian carcinoma }\end{array}$ & $\begin{array}{c}20(77 \%) \\
6(23 \%) \\
2(8 \%) \\
1(4 \%) \\
1(4 \%) \\
2(8 \%) \\
0\end{array}$ & $\begin{array}{c}18(70 \%) \\
8(30 \%) \\
1(4 \%) \\
5(19 \%) \\
0 \\
1(4 \%) \\
1(4 \%)\end{array}$ & $\begin{array}{c}52(100 \%) \\
0 \\
0 \\
0 \\
0 \\
0 \\
0\end{array}$ & $<0.05$ \\
\hline $\begin{array}{l}\text { Indication for surgery } \\
\text { Anastomotic fistula } \\
\text { Vaginal fistula } \\
\text { Urinary fistula } \\
\text { First rectal resection for } \\
\text { adenocarcinoma }\end{array}$ & $\begin{array}{c}10(38 \%) \\
11(42 \%) \\
5(20 \%) \\
0\end{array}$ & $\begin{array}{c}13(50 \%) \\
11(42 \%) \\
2(8 \%) \\
0\end{array}$ & $\begin{array}{c}0 \\
0 \\
0 \\
52(100 \%)\end{array}$ & \\
\hline Diverting stoma after surgery & $20(77 \%)$ & $26(100 \%)$ & $52(100 \%)$ & $<0.05$ \\
\hline $\begin{array}{l}\text { Interval between surgery and stoma } \\
\text { closure (in months) } \\
\text { Delay }<1 \text { year after stoma closure }\end{array}$ & $\begin{array}{l}2.4(\mathrm{IQR} 2.0-3.1) \\
\qquad 5(19 \%)\end{array}$ & $\begin{array}{c}2.6(\mathrm{IQR} 2.1-3.6) \\
3(12 \%)\end{array}$ & $\begin{array}{c}3.1(\text { IQR } 2.2-4.4) \\
4(8 \%)\end{array}$ & 0.32 \\
\hline $\begin{array}{l}\text { Colonic lengthening procedure } \\
\text { Toupet or Deloyer procedure }\end{array}$ & $8(31 \%)$ & $12(46 \%)$ & 0 & 0.19 \\
\hline $\begin{array}{l}\text { Mean number of previous } \\
\text { anastomoses }\end{array}$ & $1.3 \pm 0.9(0-4.0)$ & $1.1 \pm 0.6(0-3.0)$ & 0 & \\
\hline $\begin{array}{l}\text { Type of colo-anal anastomosis } \\
\text { DCAA } \\
\text { ICAA }\end{array}$ & $\begin{array}{c}26(100 \%) \\
0\end{array}$ & $\begin{array}{c}0 \\
26(100 \%)\end{array}$ & $\begin{array}{l}0 \\
0\end{array}$ & \\
\hline $\begin{array}{l}\text { CAA } \\
\text { straight anastomosis } \\
\text { J-pouch reservoir } \\
\text { Latero-terminal } \\
\text { anastomosis } \\
\text { Manual anastomosis } \\
\text { Mechanical anastomosis }\end{array}$ & $\begin{array}{c}0 \\
0 \\
0 \\
26(100 \%) \\
0\end{array}$ & $\begin{array}{c}0 \\
0 \\
0 \\
26(100 \%) \\
0\end{array}$ & $\begin{array}{c}4(8 \%) \\
27(52 \%) \\
21(40 \%) \\
37(71 \%) \\
15(29 \%)\end{array}$ & $<0.015$ \\
\hline
\end{tabular}

Abbreviations: DCAA= redo surgery with delayed colo-anal anastomosis (group A); ICAA: redo surgery with immediate colo-anal anastomosis (group B); CAA: first colo-anal anastomosis for cancer (group C) 
Table 2. Functional results evaluated with LARS score and GIQLI score in the three groups of patients at the end of the follow-up and for the two subgroups: $>$ or $<2$ years.

\begin{tabular}{lccc}
\hline Functional results & Group A (n=26) & Group B (n=26) & Group C (n=52) \\
\hline$\leq \mathbf{2 4}$ months since stoma closure & 13 & 13 & 27 \\
Number of patients & $30(\mathrm{IQR} 14-41)$ & $23(\mathrm{IQR} 0-41)$ & $22(\mathrm{IQR} 11-37)$ \\
Median LARS score & $3(23 \%)$ & $5(38 \%)$ & $12(44 \%)$ \\
No LARS (score 0-20) & $3(23 \%)$ & $3(23 \%)$ & $4(15 \%)$ \\
Minor LARS (score 21-29) & $7(54 \%)$ & $5(38 \%)$ & $11(41 \%)$ \\
Major LARS (score 30-42) & $110(\mathrm{IQR} 83-135)$ & $109(\mathrm{IQR} 81-135)$ & $120(\mathrm{IQR} 90-150)$ \\
Median GIQLI score & & & \\
$\mathbf{2 4}$ months since stoma closure & 13 & 13 & 25 \\
Number of patients & $21(\mathrm{IQR} 11-35)$ & $18(\mathrm{IQR} 5-26)$ & $13(\mathrm{IQR} 9-20)$ \\
Median LARS score & $7(54 \%)$ & $8(61 \%)$ & $19(76 \%)$ \\
No LARS (score 0-20) & $1(8 \%)$ & $3(23 \%)$ & $3(12 \%)$ \\
Minor LARS (score 21-29) & $5(38 \%)$ & $2(16 \%)$ & $3(12 \%)$ \\
Major LARS (score 30-42) & $118(\mathrm{IQR} 91-143)$ & $112(\mathrm{IQR} 81-145)$ & $129(\mathrm{IQR} 111-145)$ \\
Median GIQLI score & & & \\
At the end of the follow-up & 26 & 26 & 52 \\
Number of patients & $25(\mathrm{IQR} 13-38)$ & $20(\mathrm{IQR} 7-34)$ & $19(\mathrm{IQR} 15-32)$ \\
Median LARS score & $10(38 \%)$ & $13(50 \%)$ & $31(59 \%)$ \\
No LARS (score 0-20) & $4(16 \%)$ & $6(23 \%)$ & $7(14 \%)$ \\
Minor LARS (score 21-29) & $12(46 \%)$ & $7(27 \%)$ & $14(27 \%)$ \\
Major LARS (score 30-42) & $120(\mathrm{IQR} 105-138)$ & $119(\mathrm{IQR} 98-139)$ & $128(\mathrm{IQR} 108-144)$ \\
Median GIQLI score & &
\end{tabular}

Abbreviations: DCAA= redo surgery with delayed colo-anal anastomosis (group A); ICAA: redo surgery with immediate colo-anal anastomosis (group B); CAA: first colo-anal anastomosis for cancer (group C) 
Table 3. Details of GIQLI and LARS scores in the 3 groups of patients at the end of the follow-up.

\begin{tabular}{|c|c|c|c|c|c|}
\hline LARS score & $\mathbf{A}$ & B & $\mathbf{C}$ & A vs. B & $\begin{array}{l}\text { Redo surgery } \\
\text { vs. C } \\
\end{array}$ \\
\hline Gas incontinence & $\begin{array}{l}7(\text { IQR } 1-7) \\
4.65 \pm 3.07\end{array}$ & $\begin{array}{c}4(\mathrm{IQR} 0-7) \\
3.85 \pm 3.12\end{array}$ & $\begin{array}{l}4(\mathrm{IQR} 2-7) \\
3.38 \pm 3.22\end{array}$ & $\mathrm{p}=0.31$ & $\mathrm{p}=0.17$ \\
\hline Stool incontinence & $\begin{array}{l}3 \text { (IQR 3-3) } \\
2.31 \pm 1.29\end{array}$ & $\begin{array}{l}3(\text { IQR } 0-3) \\
2.08 \pm 1.41\end{array}$ & $\begin{array}{c}1.5(\text { IQR } 0-3) \\
1.5 \pm 1.51\end{array}$ & $\mathrm{p}=0.54$ & $\mathrm{p}=0.016$ \\
\hline Frequency of stools & $\begin{array}{c}2(\text { IQR } 0-4) \\
1.92 \pm 1.81\end{array}$ & $\begin{array}{c}2(\mathrm{IQR} 0-3.5) \\
1.73 \pm 1.89\end{array}$ & $\begin{array}{l}0(\mathrm{IQR} 0-2) \\
1.48 \pm 1.86\end{array}$ & $\mathrm{p}=0.69$ & $\mathrm{p}=0.309$ \\
\hline Fragmentation & $\begin{array}{c}9(\text { IQR } 2.25-1.1) \\
7.5 \pm 4.72\end{array}$ & $\begin{array}{c}9(\mathrm{IQR} 0-11) \\
6.58 \pm 4.95\end{array}$ & $\begin{array}{c}11(\mathrm{IQR} 9-11) \\
8.15 \pm 4.56\end{array}$ & $\mathrm{p}=0.41$ & $\mathrm{p}=0.065$ \\
\hline Urgency & $\begin{array}{c}11(\text { IQR } 0-16) \\
8.46 \pm 7.58\end{array}$ & $\begin{array}{c}0 \text { (IQR 0-14.7) } \\
6.42 \pm 7.28\end{array}$ & $\begin{array}{c}0(\text { IQR } 0-11) \\
4.86 \pm 6.90\end{array}$ & $\mathrm{p}=0.30$ & $\mathrm{p}=0.071$ \\
\hline GIQLI score & $\mathbf{A}$ & B & $\mathbf{C}$ & A vs. B & $\begin{array}{l}\text { Redo surgery } \\
\text { vs. C }\end{array}$ \\
\hline Symptoms & 64 (IQR 58-70) & 65 (IQR 61-70) & 71 (IQR 64-76) & $\mathrm{p}=0.59$ & $p=0.047$ \\
\hline Physical condition & 21 (IQR 16-27) & 24 (IQR 18-27) & 27 (IQR 22-28) & $\mathrm{p}=0.51$ & $\mathrm{p}=0.039$ \\
\hline Emotions & 19 (IQR 15-20) & 15 (IQR 11-20) & 18 (IQR 14-20) & $\mathrm{p}=0.028$ & $\mathrm{p}=0.86$ \\
\hline Social integration & 16 (IQR 12-20) & 17 (IQR 14-20) & 18 (IQR 15-20) & $\mathrm{p}=0.047$ & $\mathrm{p}=0.27$ \\
\hline Alimentation & 2 (IQR 2-4) & 3 (IQR 2-4) & 3 (IQR 2-4) & $\mathrm{p}=0.71$ & $\mathrm{p}=0.16$ \\
\hline Sexual life & 2 (IQR 1-4) & 2 (IQR 1-4) & 3 (IQR 2-4) & $\mathrm{p}=0.75$ & $\mathrm{p}=0.015$ \\
\hline
\end{tabular}

Abbreviations: DCAA= redo surgery with delayed colo-anal anastomosis (group A); ICAA: redo surgery with immediate colo-anal anastomosis (group B); CAA: first colo-anal anastomosis for cancer (group C) 
Table 4. Predictive factors of major LARS score in univariate analysis after redo surgery and first colo-anal anastomosis (group C).

\begin{tabular}{lcc}
\hline & Redo surgery $(\mathbf{n}=\mathbf{5 2})$ & $\mathbf{C}(\mathbf{n}=\mathbf{5 2})$ \\
\hline Gender & $\mathrm{p}=0.30$ & $\mathrm{p}=0.026$ \\
Previous pelvic radiotherapy & $\mathrm{p}=0.026$ & $\mathrm{p}=0.022$ \\
Interval from stoma closure $>\mathbf{2}$ years & $\mathrm{p}<0.01$ & $\mathrm{p}<0.01$ \\
Number of previous anastomoses $>\mathbf{2}$ & $\mathrm{p}=0.34$ & - \\
Colonic lengthening procedure & $\mathrm{p}=0.74$ & - \\
\hline
\end{tabular}

Abbreviations: group $\mathrm{C}=$ first colo-anal anastomosis for cancer 
Figure Legends:

Figure 1a \& 1b. Comparison of LARS and GIQLI scores in the three groups of patients at the end of the follow-up. (A: delayed colo-anal anastomosis for redo-surgery, B: immediate colo-anal anastomosis for redo-surgery and C: first colo-anal anastomosis for cancer)

Figure $2 a$ \& $2 b$. LARS and GIQLI scores in the 3 groups of patients at the end of the follow-up (A: delayed colo-anal anastomosis for redo-surgery, B: immediate colo-anal anastomosis for redosurgery and C: first colo-anal anastomosis for cancer ) *in blue color: patients before 2 years since stoma closure, in black color patients after 2 years since stoma closure 


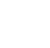
.

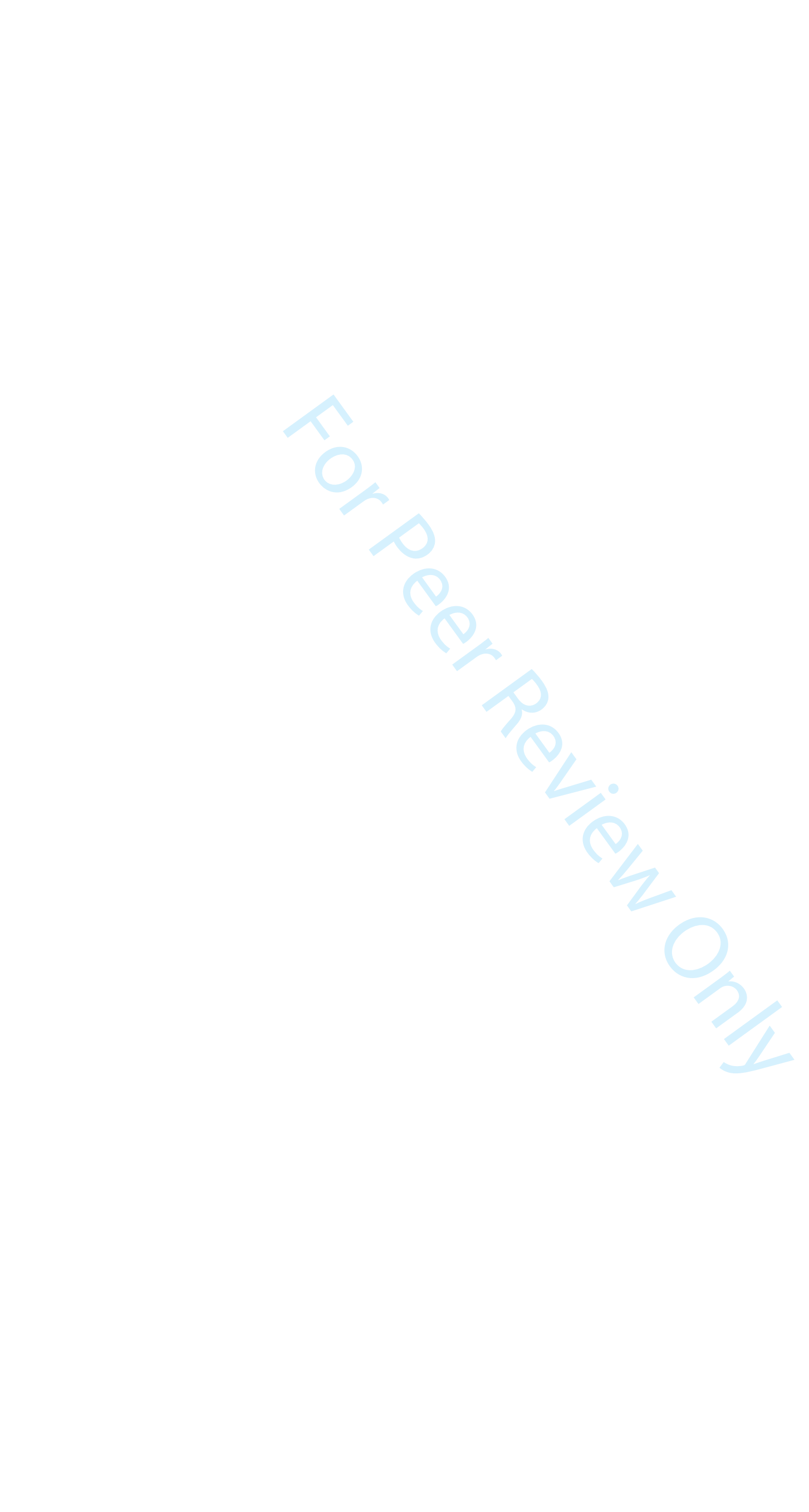
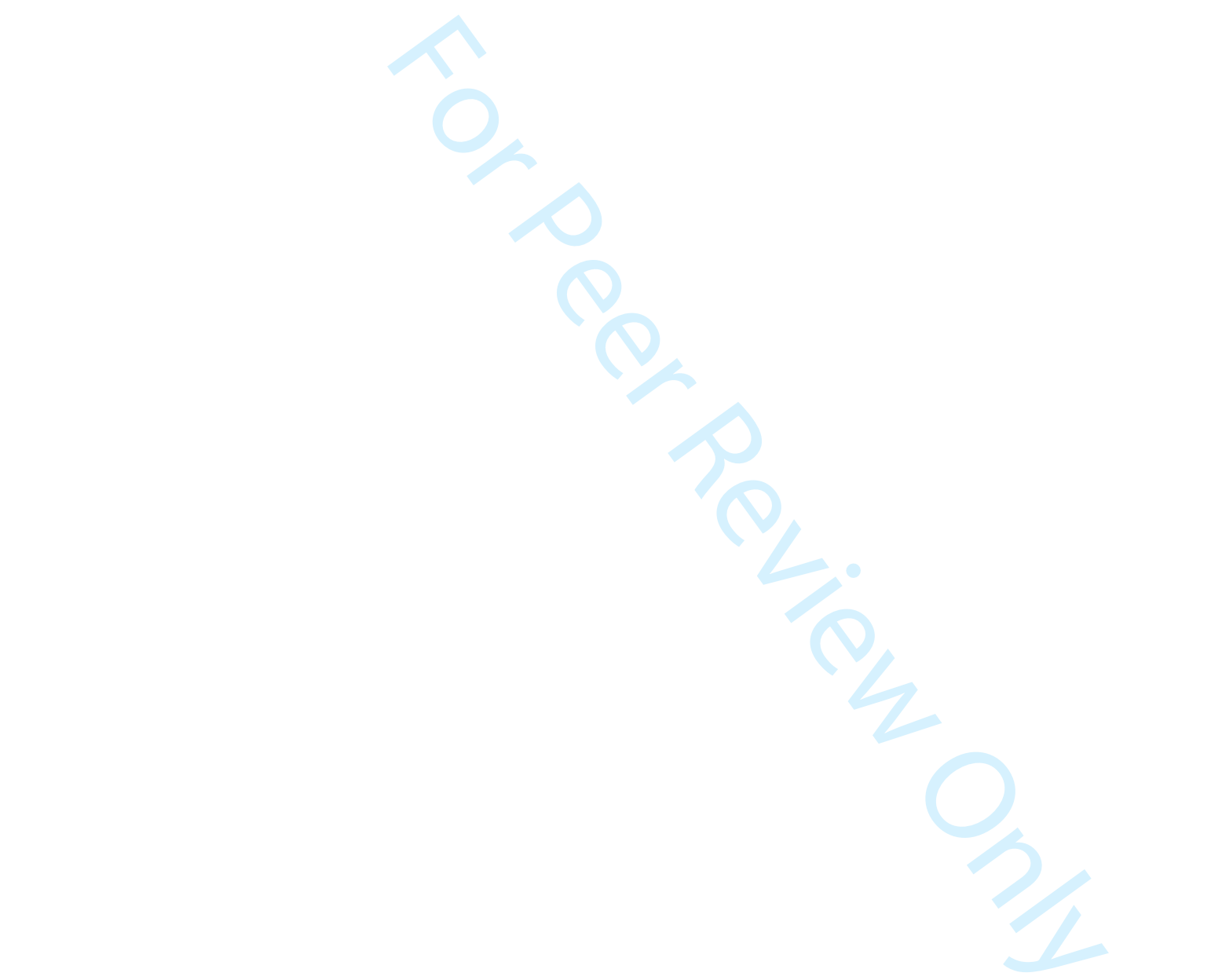
Colorectal Disease

Page 24 of 27
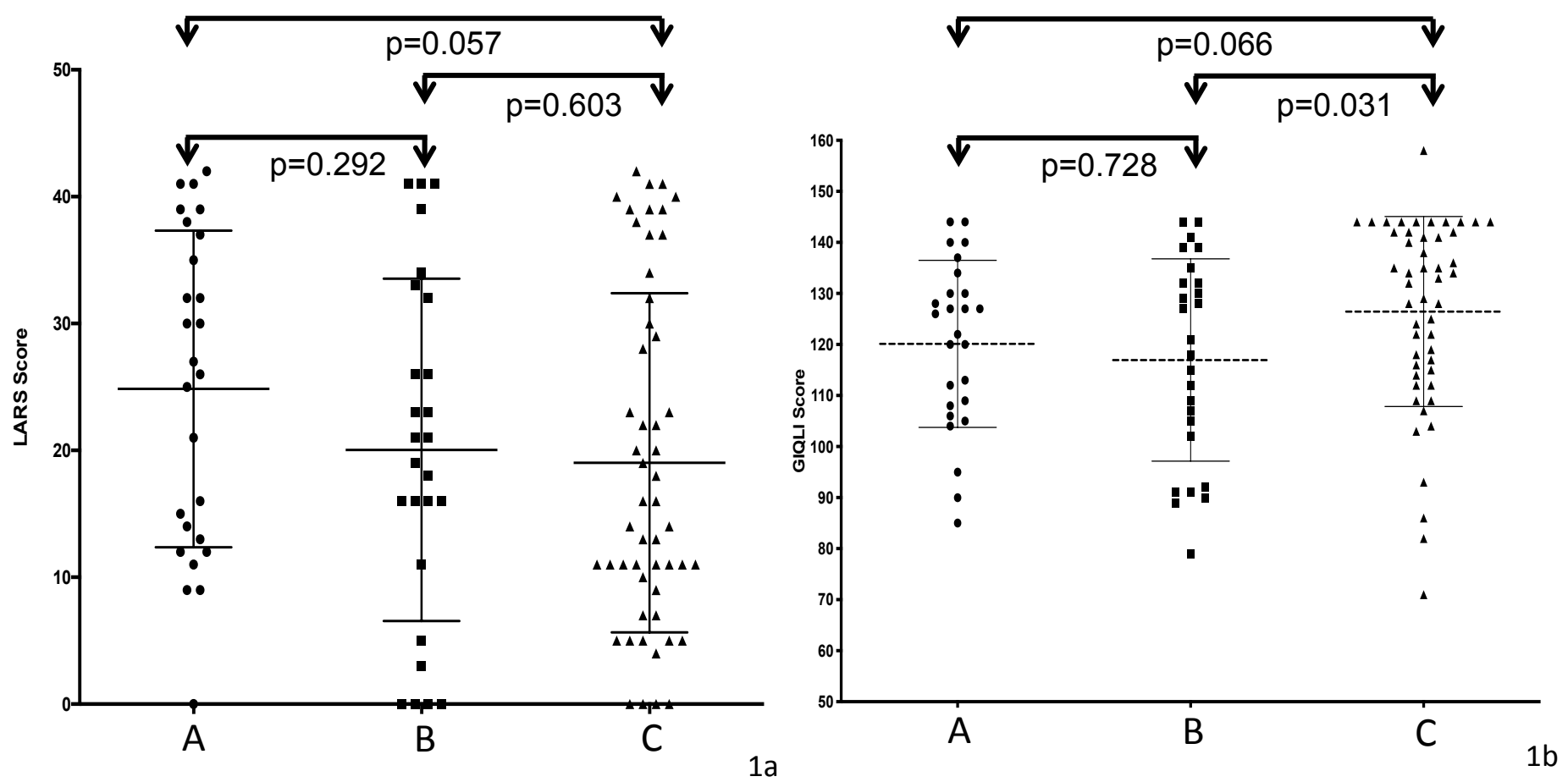

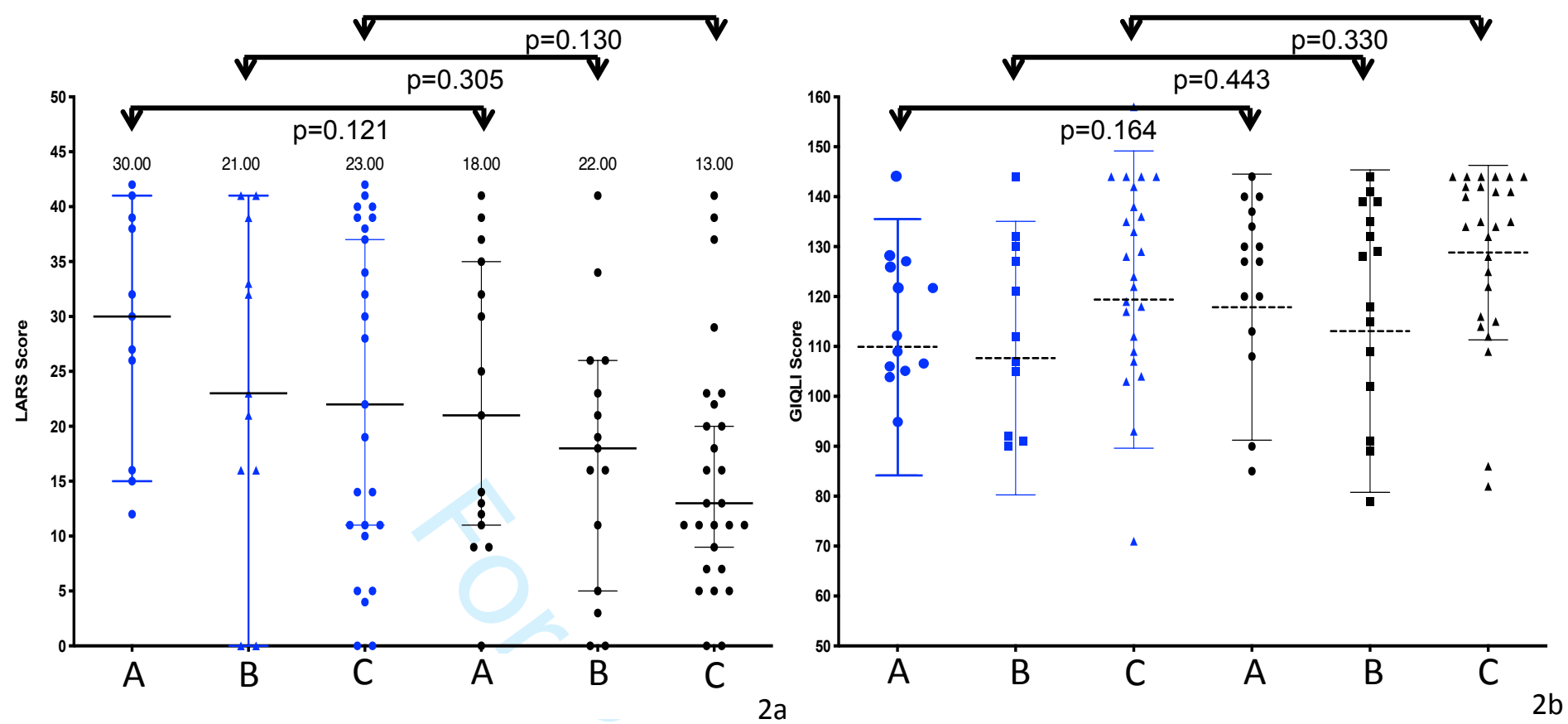
STROBE Statement - Checklist of items that should be included in reports of case-control studies

\begin{tabular}{|c|c|c|c|}
\hline & $\begin{array}{c}\text { Item } \\
\text { No }\end{array}$ & Recommendation & page \\
\hline \multirow[t]{2}{*}{ Title and abstract } & 1 & $\begin{array}{l}\text { (a) Indicate the study's design with a commonly used term in the title or } \\
\text { the abstract }\end{array}$ & $1-3$ \\
\hline & & $\begin{array}{l}\text { (b) Provide in the abstract an informative and balanced summary of } \\
\text { what was done and what was found }\end{array}$ & $1-3$ \\
\hline Introduction & & & 4-5 \\
\hline Background/rationale & 2 & $\begin{array}{l}\text { Explain the scientific background and rationale for the investigation } \\
\text { being reported }\end{array}$ & 4 \\
\hline Objectives & 3 & State specific objectives, including any prespecified hypotheses & 5 \\
\hline Methods & & & $5-7$ \\
\hline Study design & 4 & Present key elements of study design early in the paper & 5 \\
\hline Setting & 5 & $\begin{array}{l}\text { Describe the setting, locations, and relevant dates, including periods of } \\
\text { recruitment, exposure, follow-up, and data collection }\end{array}$ & 5 \\
\hline Participants & 6 & $\begin{array}{l}\text { (a) Give the eligibility criteria, and the sources and methods of case } \\
\text { ascertainment and control selection. Give the rationale for the choice of } \\
\text { cases and controls }\end{array}$ & 5 \\
\hline
\end{tabular}

(b) For matched studies, give matching criteria and the number of 5 controls per case

\begin{tabular}{|c|c|c|c|}
\hline Variables & 7 & $\begin{array}{l}\text { Clearly define all outcomes, exposures, predictors, potential } \\
\text { confounders, and effect modifiers. Give diagnostic criteria, if applicable }\end{array}$ & 6 \\
\hline $\begin{array}{l}\text { Data sources/ } \\
\text { measurement }\end{array}$ & $8^{*}$ & $\begin{array}{l}\text { For each variable of interest, give sources of data and details of } \\
\text { methods of assessment (measurement). Describe comparability of } \\
\text { assessment methods if there is more than one group }\end{array}$ & 5 \\
\hline Bias & 9 & Describe any efforts to address potential sources of bias & \\
\hline Study size & 10 & Explain how the study size was arrived at & 7 \\
\hline Quantitative variables & 11 & $\begin{array}{l}\text { Explain how quantitative variables were handled in the analyses. If } \\
\text { applicable, describe which groupings were chosen and why }\end{array}$ & 7 \\
\hline \multirow[t]{5}{*}{ Statistical methods } & 12 & $\begin{array}{l}\text { (a) Describe all statistical methods, including those used to control for } \\
\text { confounding }\end{array}$ & 7 \\
\hline & & (b) Describe any methods used to examine subgroups and interactions & 7 \\
\hline & & (c) Explain how missing data were addressed & \\
\hline & & $\begin{array}{l}\text { (d) If applicable, explain how matching of cases and controls was } \\
\text { addressed }\end{array}$ & 5 \\
\hline & & (e) Describe any sensitivity analyses & 7 \\
\hline Results & & & 7-9 \\
\hline \multirow[t]{3}{*}{ Participants } & $13^{*}$ & $\begin{array}{l}\text { (a) Report numbers of individuals at each stage of study — eg numbers } \\
\text { potentially eligible, examined for eligibility, confirmed eligible, } \\
\text { included in the study, completing follow-up, and analysed }\end{array}$ & 7 \\
\hline & & (b) Give reasons for non-participation at each stage & 7 \\
\hline & & (c) Consider use of a flow diagram & 7 \\
\hline \multirow[t]{2}{*}{ Descriptive data } & $14^{*}$ & $\begin{array}{l}\text { (a) Give characteristics of study participants (eg demographic, clinical, } \\
\text { social) and information on exposures and potential confounders }\end{array}$ & 7 \\
\hline & & $\begin{array}{l}\text { (b) Indicate number of participants with missing data for each variable } \\
\text { of interest }\end{array}$ & 7 \\
\hline Outcome data & $15^{*}$ & Report numbers in each exposure category, or summary measures of & 7 \\
\hline
\end{tabular}


exposure

Main results

16

(a) Give unadjusted estimates and, if applicable, confounder-adjusted estimates and their precision (eg, 95\% confidence interval). Make clear which confounders were adjusted for and why they were included

(b) Report category boundaries when continuous variables were categorized

(c) If relevant, consider translating estimates of relative risk into 7 absolute risk for a meaningful time period 


\begin{tabular}{lclll}
\hline Other analyses & 17 & $\begin{array}{l}\text { Report other analyses done-eg analyses of subgroups and interactions, and } \\
\text { sensitivity analyses }\end{array}$ & & 9-13 \\
\hline Discussion & & & 10 \\
\hline Key results & 18 & Summarise key results with reference to study objectives & 11 \\
\hline Limitations & 19 & $\begin{array}{l}\text { Discuss limitations of the study, taking into account sources of potential bias or } \\
\text { imprecision. Discuss both direction and magnitude of any potential bias }\end{array}$ & $12-$ \\
\hline Interpretation & 20 & $\begin{array}{l}\text { Give a cautious overall interpretation of results considering objectives, limitations, } \\
\text { multiplicity of analyses, results from similar studies, and other relevant evidence }\end{array}$ & 13 \\
\hline Generalisability & 21 & $\begin{array}{l}\text { Discuss the generalisability (external validity) of the study results } \\
12-\end{array}$ & 13 \\
\hline
\end{tabular}

\section{Other information}

Funding 22 Give the source of funding and the role of the funders for the present study and, if applicable, for the original study on which the present article is based

*Give information separately for cases and controls.

Note: An Explanation and Elaboration article discusses each checklist item and gives methodological background and published examples of transparent reporting. The STROBE checklist is best used in conjunction with this article (freely available on the Web sites of PLoS Medicine at http://www.plosmedicine.org/, Annals of Internal Medicine at http://www.annals.org/, and Epidemiology at http://www.epidem.com/). Information on the STROBE Initiative is available at http://www.strobe-statement.org. 